\title{
Deteksi Pelanggaran Zebra Cross Pada Traffic Light Menggunakan Metode Adaptif Background Subtraction
}

\author{
${ }^{1}$ Pami Ruli Setiawan, ${ }^{2}$ Sri Ratna Sulistiyanti, ${ }^{3}$ Syaiful Alam \\ Jurusan Teknik Elektro Universitas Lampung \\ Jalan Prof. Soemantri Brojonegoro No.1 Bandar Lampung 35145 \\ ${ }^{1}$ Pami. setiawan@gmail.com
}

Intisari - Pelanggaran zebra cross sering terjadi di Indonesia. Salah satu jenis pelanggaran zebra cross yang sering mengakibatkan kecelakaan lalu lintas adalah pengendara melanggar atau menerobos Traffic Light saat lampu merah menyala. Untuk mengatasi masalah pelanggaran tersebut ialah dengan sebuah sistem pendeteksi pelanggaran zebra cross. Pada penelitian ini dibuat sistem deteksi zebra cross dengan menggunakan metode adaptive Background Subtraction menggunakan Raspberry Pi 3. Metode adaptive Background Subtraction digunakan untuk memproses citra berisi objek yang ditangkap pada traffic light menggunakan kamera, citra yang diperoleh dapat menangkap objek yang melanggar garis line deteksi. Kemudian hasil objek yang ditangkap saat melanggar akan diberikan peringatan berupa buzzer. Hasil pengujian menunjukan bahwa model deteksi pelanggaran zebra cross berhasil mengklasifikasikan objek yang melanggar, mampu memberikan peringatan objek yang melangggar melalui buzzer secara otomatis.

Kata Kunci - Pelanggaran, Adaptif Background Substraction, Traffic Light, Raspberry Pi 3.

Abstract - Zebra cross violations often occur in Indonesia. One type of the zebra cross violation that often results in traffic accidents is the driver breaks through the Traffic Light when the red light is on. To overcome this violation problem, a detection system for zebra crossing is needed. In this study, a system for detecting zebra cross violations was made using Raspberry Pi 3 based on the adaptive Background Subtraction method. The adaptive Background Subtraction method is used to process images containing objects captured on a traffic light by the camera. From the image, processing results can be obtained an object that violates the zebra cross. And then, the object of which was captured when the violation will be given warning a buzzer sound. The test results showed that the zebra cross violation detection model succeeded in classifying the violating object, able to give an alert to objects that violated using the buzzer sound automatically.

Keyword - Violation, Adaptive Background Subtraction, Traffic Light, Raspberry Pi 3. 


\section{PENDAHULUAN}

Di Indonesia, jumlah pengguna kendaraan bermotor semakin meningkat tiap tahun. Peningkatan ini tidak diimbangi dengan volume jalan yang tetap. Hal ini mengakibatkan kemacetan lalu lintas. Selain penambahan jumlah kendaraan kemacetan dapat disebabkan oleh pengatur lampu lalu lintas yang tidak berkerja secara optimal dan adanya pelanggaran lalu lintas oleh pengendara. Salah satu jenis pelanggaran lalu lintas yang banyak terjadi adalah pengendara melanggar atau menerobos Traffic Light saat kondisi lampu merah akan menyala.

Salah satu solusi alternatif dalam meminimalisir pelanggaran di persimpangan jalan yaitu dengan menerapkan deteksi pelanggaran zebra cross dengan metode adaptive background subtraction. Metode ini mendeteksi adanya pelanggaran zebra cross pada traffic light menggunakan kamera. Kamera tersebut digunakan sebagai alat masukan yang menangkap gambar adanya pelanggaran zebra cross. Penelitian ini menggunakan pengendali utama Raspberry Pi 3 dengan sistem peringatan berupa buzzer.

Penelitian mengenai metode adaptif background subtraction sudah banyak dilakukan oleh penelitian-penelitian sebelumnya. Penelitian sebelumnya menggunakan metode ini untuk mendeteksi keberadaan objek bawah air (M.R. Prabowo, 2017). Pada pendeteksian bawah air perubahan latar belakang terjadi akibat adanya gelombang air, perubahan intensitas cahaya, dan adanya objek-objek kecil yang harus dideteksi sebagai latar belakang. Penelitian lainnya adalah menggunakan metode ini untuk mengurangi perubahan-perubahan kecil pada latar belakang karena latar belakang bersifat dinamis (F.X. A. Setyawan, 2015). Perubahan-perubahan kecil yang terjadi pada latar belakang dinamis misalnya gerakan daun akibat angin dan tetesan air hujan.

Penelitian sebelumnya mengenai pendeteksi pelanggaran pada zebra cross juga telah banyak dilakukan. Penelitian sebelumnya menggunakan sensor pendeteksi photodiode dan webcam untuk menangkap gambar pelanggaran
(Kuncoro Wongso Halim, dkk., 2016). Berbeda dengan penellitian ini, metode yang diusulkan ini menggunakan kamera sebagai sensor visual dan pengolahan data dilakukan menggunakan Raspberry pi 3. Jika terjadi pelanggaran zebra cross maka akan dibunyikan buzzer.

Penelitian tentang deteksi zebra cross menggunakan pengolahan citra telah dilakukan sebelumnya. Salah satunya penggunaan metode self similarity untuk mendeteksi zebra cross (Wang, C. dkk, 2015). Pada penelitian ini selfsimilarity dipergunakan untuk mendeteksi adanya zebra cross sedangkan pada penelitian yang dilakukan zebra cross diasumsikan sudah diketahui dan posisinya ditentukan menggunakan garis bantu.

Penelitian yang dilakukan hanya akan mendeteksi adanya pelanggar lalu lintas dan memberikan peringatan berupa suara melalui buzzer. Pelanggaran terjadi jika lampu traffic light sedang dalam kondisi menyala merah dan kendaraan melewati batas zebra cross.

\section{METODE PENELITIAN}

Penelitian ini menggunakan Raspberry Pi 3 sebagai processor dengan quad core 1,5 Ghz. Program pengendali tersebut menggunakan library Open $C V$ pada Bahasa Pemrograman Python. LED sebagai lampu Traffic Light. Buzzer sebagai memberikan peringatan bahwa objek melakukan pelanggaran zebra cross. Blok diagram sistem pada penelitian diperlihatkan pada Gambar 1.

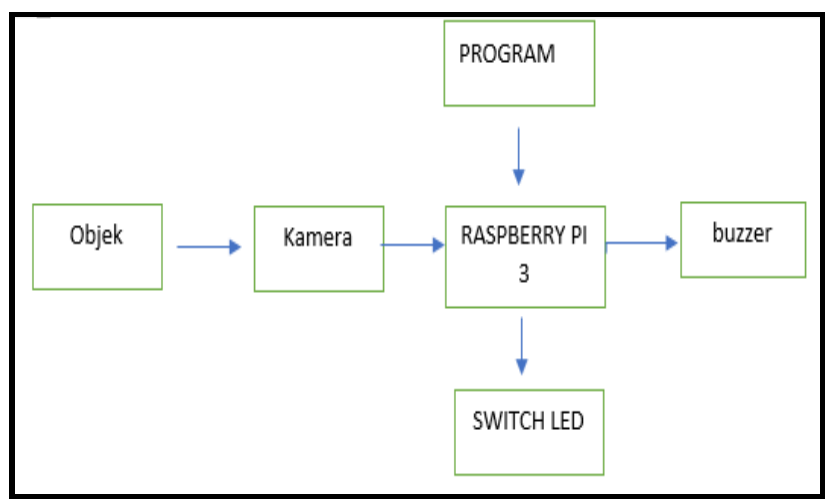

Gbr 1. Blok diagram system 


\section{A. Proses Pengambilan Video}

Video pelanggaran lalu lintas diperoleh dari kamera yang ditempatkan di atas posisi zebra cross. Posisi kamera diperlihatkan pada Gambar 2. Video yang diperoleh dikirimkan ke Raspberry untuk dilakukan pemisahan tiap frame untuk dibandingkan dengan latar belakang.

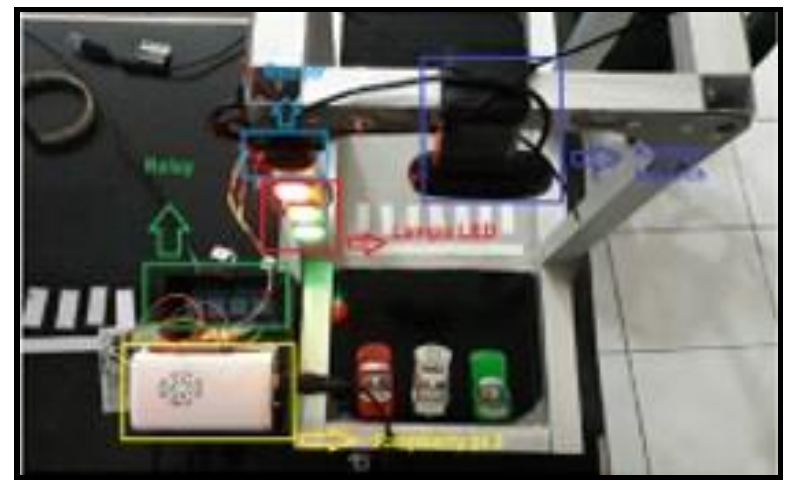

Gbr 2. Rancangan sistem pendeteksi pelanggaran lalu lintas.

1) Pengolahan Awal

Pada tahap ini data video dari kamera diubah menjadi bentuk frame-frame citra warna. Citra warna ini diubah menjadi citra aras kelabu dan dilakukan penghapusan derau untuk meminimalkan derau yang akan dideteksi sebagai objek. Proses pengubahan menjadi citra aras kelabu menggunakan persamaan (1).

$f_{b(x, y)}=0,298 \mathrm{R}+0,5870 \mathrm{G}+0,1141 \mathrm{~B}$

dimana $f_{b(x, y)}$ menyatakan citra aras kelabu. $\mathbf{R}$ adalah menyatakan intensitas warna merah, $G$ menyatakan intensitas warna hijau, dan B menyatakan intensitas warna biru.

2) Pemodelan Latar Belakang

Pemodelan latar belakang dilakukan untuk mendapatkan latar belakang yang selalu berubah berdasarkan perubahan yang mungkin dialaminya. Sehingga dapat dikatakan, latar belakang yang dipergunakan merupakan latar belakang yang adaptif. Secara matematis pemodelan latar belakang ditunjukkan melalui persamaan (2).

$$
B(x, y, t)=\alpha f(x, y, t)-(1-\alpha) B(x, y, \mathrm{t}-1)
$$

Dimana $\alpha$ adalah koefisien pembaruan, $f(x, y, t)$ adalah nilai intensitas keabuan pixel dalam frame saat ini. $B(x, y, t)$ adalah latar belakang saat ini dan $B(x, y, t-1)$ adalah nilai latar belakang sebelumnya. Model latar belakang pada metode ini selalu diperbaharui dan dipengaruhi oleh perubahan frame saat ini.

\section{3) Pendeteksian Objek}

Pendeteksian objek dilakukan dengan mengurangkan citra frame saat ini dengan citra latar belakang sebelumnya. Secara matematis pengurangan frame saat ini dengan citra latar belakang sebelumnya ditunjukkan melalui persamaan (3).

$$
H(x, y, t)=f(x, y, t)-B(x, y, t-1)
$$

Dimana $H(x, y, t)$ adalah citra hasil pengurangan, $f(x, y, t)$ adalah frame saat ini, dan $B(x, y, t-1)$ adalah latar belakang sebelumnya. Untuk menentukan apakah piksel adalah objek atau bukan dilakukan proses pengambangan (Thresholding) sehingga citra menjadi citra biner dimana piksel putih merupakan piksel bagian objek dan piksel hitam merupakan piksel bagian latar belakang. Persamaan matematis proses pengambangan diperlihatkan pada persamaan (4).

$$
o(x, y, t)= \begin{cases}1 & \text { jika } H(x, y, t) \geq T \\ 0 & \text { jika } H(x, y, t)<T\end{cases}
$$

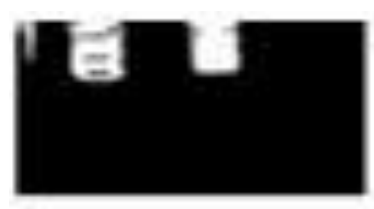

a)

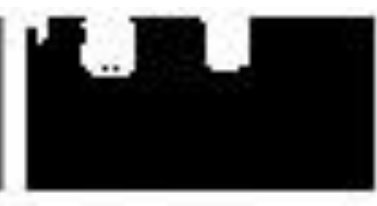

b)
Gbr 3. Hasil proses pengambangan a) Citra hasil pengurangan b) Citra hasil pengambangan

Dimana $\mathrm{O}(\mathrm{x}, \mathrm{y}, \mathrm{t})$ adalah hasil deteksi objek yang berupa citra biner dan $\mathrm{T}$ adalah nilai ambang (Threshold) yang ditentukan. Pada penelitian ini nilai $\mathrm{T}$ ditentukan sebesar 127 sehingga jika terdapat piksel bernilai kurang dari 127 maka akan diset bernilai 0 (hitam). 


\section{HASIL DAN PEMBAHASAN}

Penelitian ini dilakukan di laboratorium Elektronika Jurusan Tekni Elektro. Pengambilan data video dilakukan pada waktu pagi, siang, dan sore hari masing-masing selama 3 menit dengan 30 frame per second atau masing-masing video terdiri dari 5400 frame. Raspberry Pi 3 berfungsi sebagai alat pengendali utama atau sebagai prosesor. Lampu LED menggunakan tegangan $220 \mathrm{~V}$ karena sudah menyerupai traffic Light. Relay digunakan untuk mengendalikan ON/OFF digunakan untuk mengendalikan Lampu LED 3 warna menggunakan program yang ada di Raspberry Pi.

\section{A. Hasil Perolehan Citra}

Pengambilan citra dilakukan menggunakan coding pada pemprograman python 2.7 dengan sistem operasi Raspberry Pi 3. Citra didapatkan dengan intensitas cahaya sebesar 8,27, 45 lux dan 90 lux pada beberapa kondisi diantaranya pagi, siang, dan sore. Hasil perolehan awal yaitu sebuah citra video berdurasi 3 menit dengan frame rate 30 fps maka didapatkan total frame berjumlah 200 frame pada setiap kondisi. Contoh perolehan citra yang didapatkan kondisi pagi, siang sore hari diperlihatkan pada gambar 4. Hasil latar belakang yang diperoleh untuk pengambilan waktu di pagi hari berbeda dengan waktu pengambilan di siang hari demikian pula untuk pengambilan waktu di sore hari. Oleh karena itu perlu dilakukan pemodelan latar belakang supaya dapat beradaptasi dengan perubahan ini.

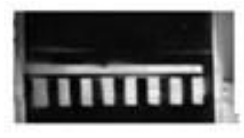

a)

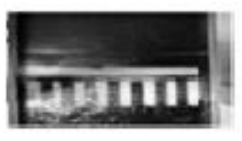

b)

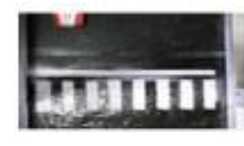

c)
Gbr 4 (a) Hasil perolehan Citra pada kondisi pagi hari dengan intensitas cahaya 8,72 Lux, (b) citra

kondisi siang hari dengan intensitas cahaya 45 Lux, dan (c) citra kondisi sore hari dengan intensitas cahaya 90 Lux.

\section{B. Hasil Pengolahan Awal}

Pengolahan awal pada citra adalah mengubah citra warna menjadi citra aras kelabu. Hal ini bertujuan untuk mereduksi matriks citra yang semula berupa 3 matriks 2D karena terdiri dari 3 warna menjadi 1 matriks $2 \mathrm{D}$ sehingga meringankan beban komputasi. Hasil pengubahan citra warna menjadi citra aras kelabu diperlihatkan pada Gambar 5.

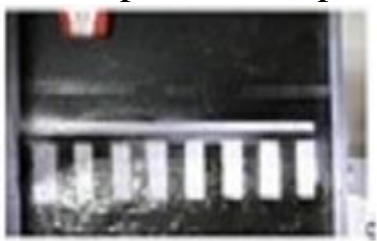

a)

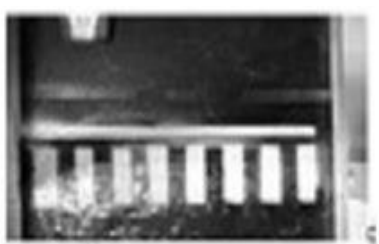

b)
Gbr 5. Hasil pengubahan citra warna RGB menjadi citra aras kelabu a) warna dan b) aras kelabu

\section{Hasil Pendeteksian Objek}

Pendeteksian objek dilakukan dengan mengurangkan frame saat ini dengan frame latar belakangnya. Jika hasil pengurangan lebih besar daripada nilai ambang yang ditetapkan maka piksel tersebutadalah bagian dari objek. Hasil pendeteksian objek diperlihatkan pada Gambar 6. Gambar 6 a) adalah citra frame saat ini dimana citra baris pertama diambil pada saat pagi hari, baris kedua diambil pada saat siang dan baris ketiga diambil pada saat sore hari. Terlihat perbedaan pada gambar zebra cross akibat perbedaan intensitas cahaya. Gambar 6 b) adalah model latar belakang dari masingmasing frame saat ini. Model latar belakang setiap saat berubah menyesuaikan perubahan kondisi latar belakang saat ini. Tujuan pemodelan latar belakang ini adalah agar objek dapat dideteksi kapan pun walau terjadi perubahan pada latar belakang akibat intensitas cahaya. Gambar 6 c) merupakan hasil pengurangan citra frame saat ini dengan model latar belakangnya. Terlihat bahwa perubahan intensitas cahaya pada latar belakangnya tidak berpengaruh pada hasil deteksi karena latar belakangnya dapat menyesuaikan perubahan intensitas cahaya ini. 

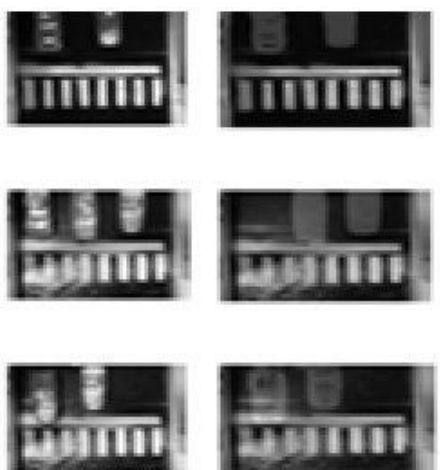

a)

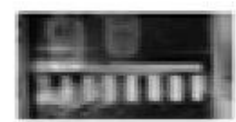

b)
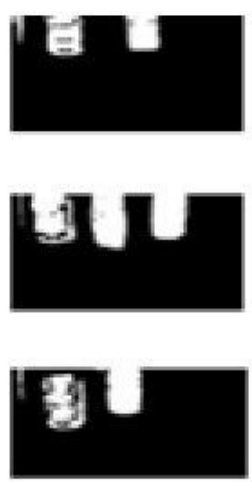

c)
Gbr 6. Proses pengurangan citra, a) Citra frame saat ini, b) Model latar belakang, dan c) citra hasil pengurangan.

Setelah dilakukan pengurangan antara frame saat ini dengan model latar belakangnya dilanjutkan dengan operasi pengambangan. Masing-masing piksel citra hasil pengurangan dibandingkan dengan nilai ambang yang diberikan sehingga hasilnya berupa objek yang dikehendaki. Hasil proses pengambangan diperlihatkan pada Gambar 7.

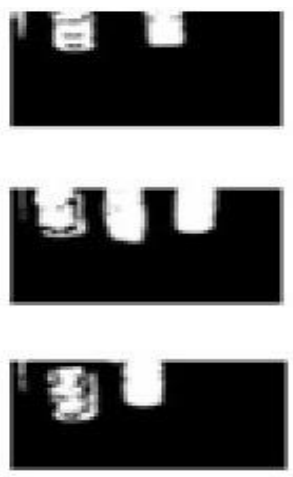

a)
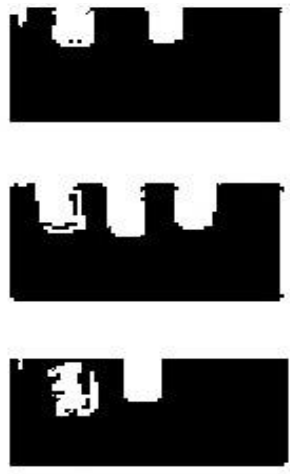

b)
Gbr 7. Proses pengambangan, a) Citra aras kelabu, dan b) Citra biner

Proses ini dilakukan secara terus menerus dari frame pertama hingga frame terakhir. Setiap frame dideteksi apakah terdapat objek didalamnya. Proses ini dilakukan oleh Raspberry sebagai mikrokomputer dengan cara menghitung setiap perubahan piksel pada frame.

\section{Penentuan Pelanggaran}

Pelanggaran terjadi jika objek dalam hal ini kendaraan melewati zebra cross saat lampu lalu lintas menyala merah. Pada penelitian ini, zebra cross telah ditentukan batasnya menggunakan garis bantu yang melintang sejajar garis sumbu $\mathrm{x}$. Posisi garis ini ditentukan karena kamera sebagai sensor visual tidak bergerak sehingga posisi zebra cross selalu tetap. Lampu lalu lintas diatur berdasarkan pewaktu yang ada di Raspberry. Saat lampu lalu lintas menyala merah maka frame pada video dibandingkan untuk mendeteksi adanya objek jika objek melewati garis yang ditentukan sebagai batas zebra cross maka buzzer akan menyala dan memberikan peringatan. Penentuan posisi garis batas zebra cross diperlihatkan pada Gambar 8 .

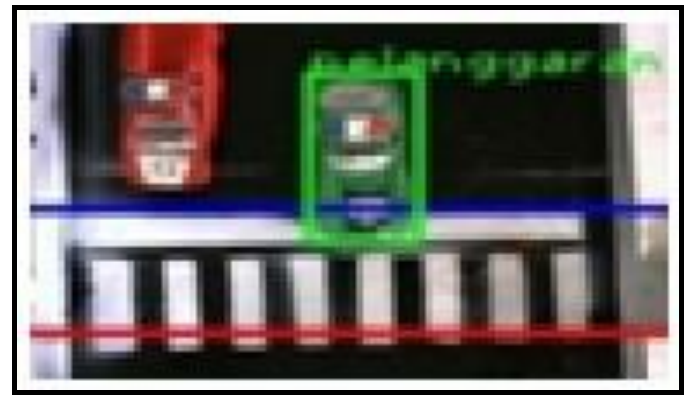

Gbr 8. Penentuan garis batas zebra cross

Garis warna biru merupakan garis batas awal zebra cross dan garis merah merupakan garis batas akhir zebra cross. Jika objek melewati garis biru maka dianggap terjadi pelanggaran sehingga objek akan diberi tanda berupa kotak dan diberi keterangan pelanggaran. Jika kondisi ini terjadi pada saat lampu lalu lintas tidak menyala merah maka tidak dilakukan pendeteksian sehingga mobil sebelah kanan tidak diberi keterangan pelanggaran.

Pada penelitian ini dilakukan 10 kali percobaan pendeteksian dengan tingkat keberhasilan $100 \%$. Setiap kali lampu lalilintas menyala merah dikondisikan adanya objek yang melanggar dan semuanya terdeteksi sebagai pelanggaran. Jika terdapat objek yang berada di belakang garis zebra cross maka dianggap tidak melakukan pelanggaran sehingga tidak diberi tanda pelanggaran (Gambar 8). 


\section{E. Pemodelan Latar Belakang Adaptif}

Pemodelan latar belakang yang adaptif dilakukan dengan mengakomodasi perubahan citra frame saat ini. Model latar belakag yang pertama selalu diubah berdasarkan frame saat ini. Perubahan ini mengikuti persamaan (2) dimana nilai $\alpha=0,2$. Hasil pemodelan latar belakang ini diperlihatkan pada Gambar 9.

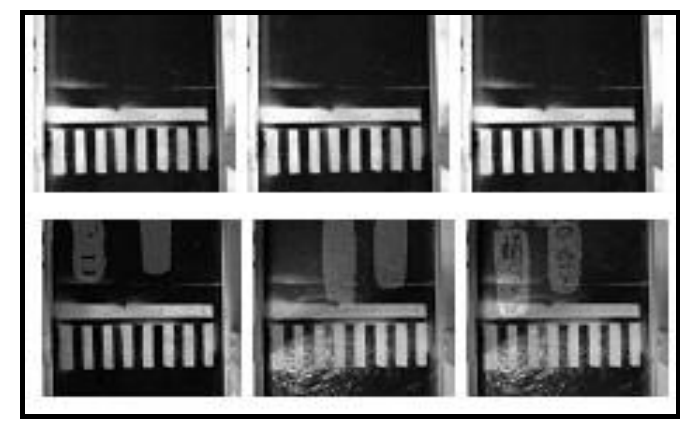

Gbr 9. Hasil pemodelan latar belakang, baris pertama masing-masing untuk latar belakang awal pagi, siang dan sore hari dan baris kedua masingmasing latar beakang adaptasi pagi, siang dan sore hari.

\section{F. Pengujian Model Pendeteksi Pelanggaran Zebracros}

Hasil latar belakang adaptasi baik pagi, siang dan sore hari memiliki citra yang berbeda dengan citra awal latar belakangnya. Perbedaan ini disebabkan karena runtunan citra frame yang selalu berubah dan mempengaruhi hasil model latar belakangnya. Jika tidak dilakukan adaptasi pada latar belakang maka perubahan intensitas cahaya dapat dianggap sebagai objek sehingga kemungkinan banyak terjadi kesalahan deteksi. Hasil pengujian model deteksi pelanggaran zebra cross yang dirancang diperlihatkan pada Tabel 1. Terdapat satu kondisi adanya derau yang masih terjadi dan terdeteksi sebagai objek ini menyebabkan kekeliruan deteksi sehingga buzzer menyala walaupun tidak terjadi pelanggaran. Pada model ini, pelanggar lalu lintas dapat diambil gambarnya tetapi dari bagian atas oleh karena itu perlu kamera tambahan untuk mengambil gambar dari bagian depan.
Tabel 1. Hasil pendeteksian pelanggaran zebra cross pada model yang dirancang.

\begin{tabular}{|c|c|c|c|}
\hline Video & $\begin{array}{c}\text { Frame } \\
\text { ke }\end{array}$ & $\begin{array}{l}\text { Citra } \\
\text { Biner }\end{array}$ & Hasil pendeteksian \\
\hline $\begin{array}{l}\text { Pagi } \\
\text { hari }\end{array}$ & 75 & & \\
\hline Pagi & 120 & & \\
\hline $\begin{array}{c}\text { Siang } \\
\text { hari }\end{array}$ & 80 & & \\
\hline $\begin{array}{l}\text { Sore } \\
\text { hari }\end{array}$ & 94 & & \\
\hline $\begin{array}{l}\text { Sore } \\
\text { hari }\end{array}$ & 168 & & \\
\hline
\end{tabular}

\section{KESIMPULAN}

Model deteksi pelanggaran zebra cross yang dirancang menggunakan metode pendeteksian adaptive background subtraction telah berhasil mendeteksi adanya kendaraan yang melakukan pelanggaran. Nyala lampu LED hijau, kuning, dan merah yang merepresentasikan lampu lalu lintas dapat diatur dengan baik menggunakan Raspberry $P i 3$ sesuai waktu yang diinginkan. Berdasarkan hasil pengujian yang telah dilakukan bahwa software pendeteksian pelanggaran zebra cross pada Traffic Light ini berkerja dengan baik. Ketika terdapat pengendara yang menerobos lampu lalu lintas pada kondisi menyala merah maka secara 
otomatis pengendara tersebut terdeteksi dan dilakukan capture pada kendaraan tersebut dan buzzer akan memberikan peringatan.

Model yang dirancang masih memungkinkan mendeteksi adanya derau sehingga menghasilkan peringatan palsu saat tidak terjadi pelanggaran lalu lintas. Perlu dilakukan penelitian lebih lanjut untuk memperbaiki kelemahan-kelemahan pada sistem. Disarankan untuk melakukan pengembangan atau perbaikan menambahkan panel surya sebagai supplay energi tambahan untuk menjaga traffic light agar tetap menyala ketika supplay utama mati. Penambahan kamera depan perlu dilakukan jika menginginkan pelanggar dapat diambil gambarnya dari bagian depan sehingga dapat diketahui informasi nomor plat pelanggar lalu lintas. Dapat pula menambahkan 2 buah kamera di setiap ruas jalan agar dapat dipergunakan untuk mengatur Timer Traffic Light dan pendeteksi zebra cross.

\section{UCAPAN TERIMA KASIH}

Terima kasih kepada Dosen-dosen di Laboratorium Elektronika dan Rumah Cerdas Kampung Digital yang telah memberikan kontribusi dalam penyelesaian penelitian ini.

\section{REFERENSI}

[1].Gonzalez, R.C., R. E. Woods (2008) Digital Image Processing, Pearson Prentice Hall, New Jersey.

[2].Prabowo, M.R., Hudayani, N.,Purwiyanti, S., Sulistiyanti, S.R., Setyawan, F.X.A.(2017) A Moving Objects Detection In Underwater Video Using Subtraction Of The Background Model, Proc. EECSI 2017, Yogyakarta, Indonesia, 19-21 September.

[3].Setyawan, F.X.A., Tan, J.K., Kim, H., Ishikawa, S.(2015) Detecting moving objects on a video having a dynamic background, proceeding of International Conference on Artificial Life and Robotics (ICAROB), 10-12 Januari, 27-31.
[4].Wang, C., Zhao, C., Wang, H. (2015) SelfSimilarity Based Zebra-Crossing Detection for Intelligent Vehicle, The Open Automation and Control Systems Journal, Vol. 7, 974-986.

[5].Wongsokuncoro.H. (2016) Rancang Bangun Pendeteksi Pelanggaran Pada Traffic Light Berbasis Mikrocontroller, Laporan Tugas Akhir Program Studi D3 Otomasi sistem Instrumentasi, Departemen Teknik, Fakultas Vokasi, Universitas Airlangga, Surabaya. 